\title{
TIMBER COLUMN SEISMIC RESPONSE DESIGN
}

\author{
Abdoullah Namdar 1,2 \\ ${ }^{1}$ Huaiyin Institute of Technology, Huai'an, China \\ ${ }^{2}$ Ton Duc Thang University, Ho Chi Minh City, Vietnam \\ (Received April 20I9)
}

\begin{abstract}
The timber column seismic response has been analyzed when it has been subjected to nearfault ground motion. The cyclic displacement and cyclic strain have been investigated. It needs to indicate in most of the literature acceleration history of earthquake used in the numerical analysis is not well clear for the reader. The results showed that the damping ratio, strain energy, and nonlinear deformation were changed in respect to the frame geometry. The innovation of this paper is to develop cycling graphs by means ABAQUS for study timber column seismic response and improve the concept of strain energy in understanding displacement mechanism.
\end{abstract}

KEYWORDS: Timber column, cyclic displacement, strain energy, nonlinear deformation.

\section{INTRODUCTION}

The earthquake is one of the natural hazards needs to investigate appropriately to enhance the infrastructural seismic design. On the other hand, each near-fault ground motion has specific characteristics. The timber beam seismic design has numerically been simulated when subjected to near-fault ground motion, with reference to small displacement theory. The inertial interaction, energy dissipation, and nonlinear deformation are analyzed. The ABAQUS has been used to simulate a number of engineering problems including timber beams and timber structure (Namdar et al. 2019, Namdar et al. 2016a, Namdar et al. 2016b, Namdar 2016a, Namdar 2016b). The numerical, experimental, analytical and theoretical methodologies have been used to explain concepts of seismic timber design, seismic resistance evaluation of traditional timber-frame damping mechanism, construction quality of composite timber-steel frame, traditional timber construction, use timber as an eco-friendly strengthening system and mechanical properties of the timber (Namdar et al. 2019, Namdar et al. 2016a, Jayne 1959, Sandoz 1989, Yeh et al. 1971, Rajčić and Bjelanović 2005, Ayala and Wang 2006, Pizzo et al. 2004, Arun 2009, Galassi et al. 2018, Androić et al. 2008, Daniūnas and Gečys 2015, Stepinac et al. 2017, Aktas et al. 2014). Among construction materials, the wood is used in the structure, and it has shown satisfactory seismic resistance (Soltis 1984, Liu et al. 2018). But the seismic design of timber column subjected to near-fault ground motions and developing cycling graph using ABAQUS and also 
the explanation of seismic behavior of timber column never has been reported in the literature. In the present study, the column is located in a single span and single floor of a timber frame with 3 -meter height. The columns of two frames with $1.5 \mathrm{~m}$ and $3 \mathrm{~m}$ span have been compared. The seismic load response-cyclic displacement, seismic load response-cyclic strain, and cyclic strain-cyclic displacement have been investigated to evaluate the damping ratio, strain energy, and nonlinear deformation.

\section{METHOD AND MATERIALS}

The timber frame is subjected to near-fault ground motion. The ABAQUS is used to executing the numerical analysis. Fig. 1 shows the near-fault ground motion is used in the numerical simulation. To explain results, a critical time of the near-fault ground motion has been zoomed and these critical times of acceleration history of the earthquake were used in numerical analysis. In the many kinds of literature acceleration history of earthquake used in the numerical analysis is not well clear for the reader. In the present study, the near-fault ground motion is zoomed. This technique simplifies the interpretation of timber column seismic behavior. Fig. $1 \mathrm{~b}$ shows the near-fault ground motion has maximum loading in $24.05 \mathrm{sec}$ and maximum reloading occurs in $24.14 \mathrm{sec}$. In the peak acceleration, there is $0.09 \mathrm{sec}$ for change direction of seismic loading. When the near-fault ground motion reached the peak level, the highest vibration is applied to the model. The seismic excitation widespread released by small-magnitude earthquakes is insignificant in seismic design of structure compared to a major earthquake. Therefore, the near-fault ground motion from $22 \mathrm{sec}$ till $26 \mathrm{sec}$ is used in the numerical analysis. The seismic load response-cyclic displacement, seismic load response-cyclic strain, and cyclic strain-cyclic displacement of the column shown in Fig. 2 have been investigated to evaluate the damping ratio, strain energy, and nonlinear deformation. The details of the timber frame have been depicted in Fig. 2. The geometry of the timber frame has been used at the numerical analysis is shown in Fig. 2. The mechanical properties of timber have been used in the numerical shows in Tab. 1 .

Tab. 1: Timber material properties (Dackermann et al. 2016).

\begin{tabular}{|c|c|c|}
\hline Young's modulus $\left(\mathrm{N} \cdot \mathrm{m}^{-2}\right)$ & Poisson's ratio & Density $\left(\mathrm{kg} \cdot \mathrm{m}^{-3}\right)$ \\
\hline $14,750 * 106$ & 0.3 & 620 \\
\hline
\end{tabular}
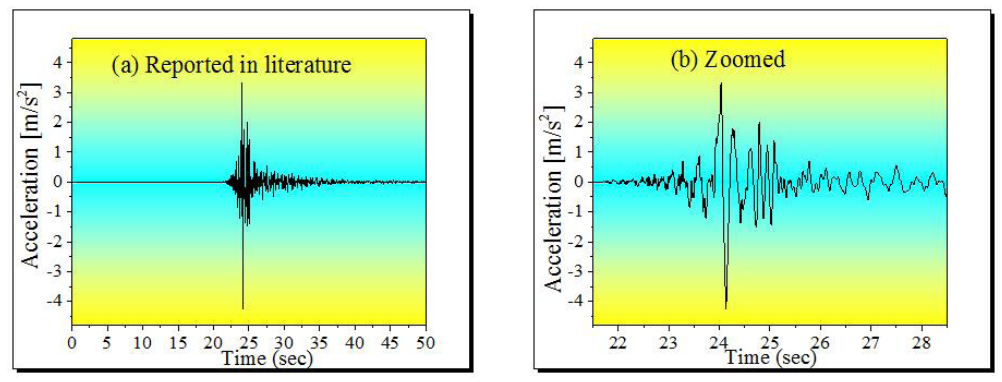

Fig. 1: Acceleration history of the earthquake has been reported in the literature (Center for Engineering Strong Motion data. https://strongmotioncenter.org). 


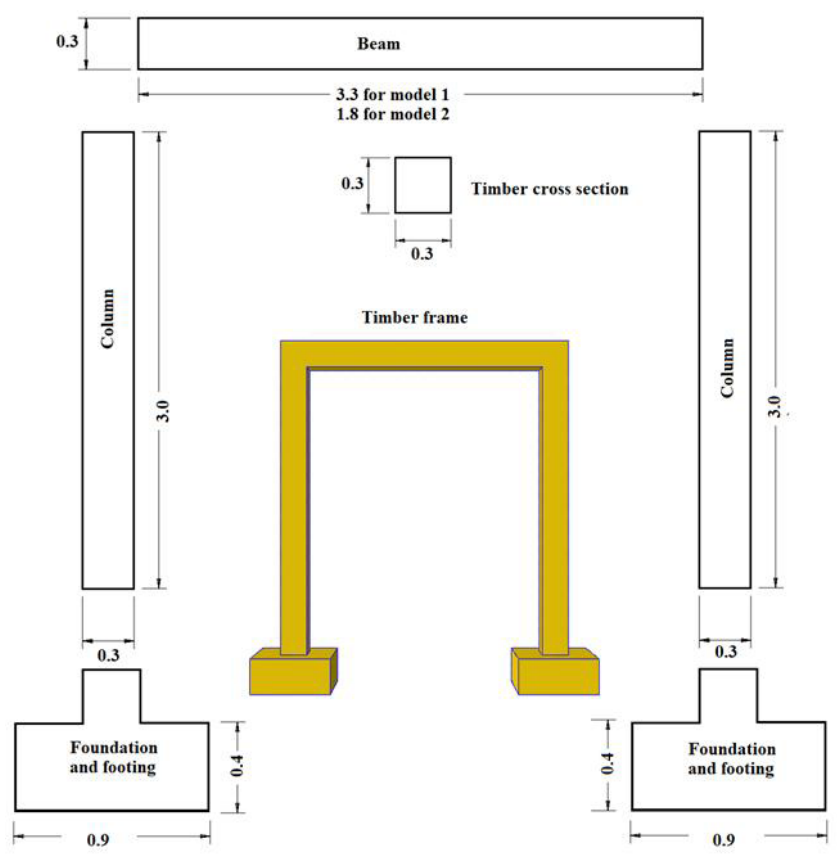

Fig. 2: The structural elements of the timber frame (dimension in meters).

\section{RESULTS AND DISCUSSION}

The cyclic nonlinear displacements have numerically been estimated using finite element method. The deformation mechanism is explained based on cyclic nonlinear displacements observed along the timber column when simulated seismic excitation was applied to the models. The seismic wave travels along the timber beams causes lateral, vertical and residual displacements, it occurs with respect to the seismic wave velocity, construction material characteristics, and frame geometry. The displacement morphology of timber column effect to timber frame seismic resistance. It has been observed that the main reason for timber frame failure was timber geometry. Fig. 3 shows the higher seismic load response and displacement were developed to timber column at model 2. The load-displacement curves show the higher nonlinear deformation in the column at model 2. The seismic wave traveling path is changed at each model. The seismic excitation widespread and cyclic nonlinear displacements cause to the reduction of timber span seismic stability and subsequently significant damage or fully collapse occurs. The deformed shape of timber column at any instant of motion represents in terms of dynamic displacement and changing with time. When the timber frame is subjected to seismic excitation the initial displacement is created. The seismic resistance of timber column is opposite an initial displacement. The geometry of frame supports in time and type of an initial displacement occurrence. It can be observed that the response cyclic load to displacement governs the timber frame vibration mechanism and modify damping ratio at each model. In comparison two models two different shapes of nonlinear displacement shown in Fig. 3. The higher nonlinear 
displacement appears at model 2 , it is due to resonance and subsequently, significantly timber column seismic resistance reduces, displacement mechanism of timber frame is changed and results in faster timber frame collapse. The peak displacement response in model 2 is higher than in model 1 . When the yield displacement capacity of the lateral load resisting system is exceeded, the strain energy internal elastic force and base shear force at each model causes modification nonlinear deformation mechanism and the cyclic load-displacement path for each model formed differently. When the timber column is subjected to seismic excitation the cyclic softening area occurs on the column and it causes specific nonlinear deformation for each column at models 1 and 2. This type of nonlinear behavior leads to the deterioration of seismic resistance of timber frame and developing large displacements. The timber column stiffness degrading hysteretic with respect to larger displacements is minimized seismic resistance of timber. Accordingly, the nonlinear deformation has been formed at softening area.
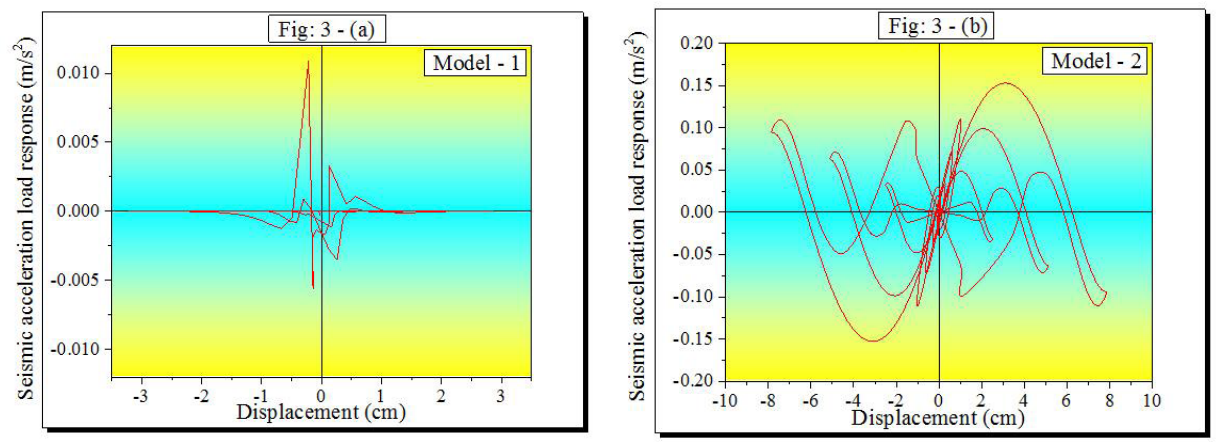

Fig. 3: Seismic response versus displacement found in timber column models 1 and 2, when the model has been subjected to near-fault ground motion.

The interpretation strain-displacement cyclic graph simplified understanding the variation of elastic displacement ratio in numerical analysis. The strain hardening is shown in Fig. 4. The strain-displacement cyclic paths show how strain energy creates displacement. The displacement deforms corresponding to change releasing strain energy. It can be observed that the high difference in peak displacement, and on another hand from the strain-displacement cyclic paths has been understood that the types of seismic excitation at each model has specific characteristics, and its effects on seismic load transferring and deterioration seismic resistance of the model. The seismic excitation type has a meaningful relationship with elastic strain and displacement. The unequal cyclic nonlinear displacements are applicable for seismic assessment and design of timber column and timber frame as well. The near-fault ground motion response in corporative with timber frame geometry induces elastic and inelastic displacement, and the yield point for each timber column is changed. The damping modified with related to the displacement mechanism. The seismic excitation releasing the strain energy and accumulating strain energy in each timber frame column causes nonlinear deformation at different parts of timber column. However, in the present study, the measurement of dissipation strain energy has been made for an evaluation damping ratio of timber column. The strain energy in model 2 is raised compared to model 1 , from this phenomenon can understand that the damping ratio in model 1 is considerably higher than model 2. The results of numerical analysis shown dissipation strain energy at a timber column with the same material and shape significantly were affected by the geometry of the timber frame. The concept of sharing loading has governed strain energy and damping ratio of 
a structural element consequently, and strain energy dramatically increases. In the design point of view arrangement, a single structural element significantly affects the safety of the structure. On the other hand in model 2 having the same mechanical properties as model 1 , the cyclic nonlinear strain was found to dramatically increases in model 2 with increasing frame span and constant height of timber column. The condition of strain-displacement cyclic paths was observed in model 1 has the lower inclination at peak level. However, sudden release strain energy increases seismic excitation of timber frame model 2. Consequently, the seismic excitation mechanism in timber frame supports to predict frame nonlinear cyclic mobility. Furthermore, the cyclic nonlinear strain versus cyclic nonlinear displacement graph shows in a timber frame subjected to a complex seismic excitation mechanism, and the permanent loss in shear strength is expected.
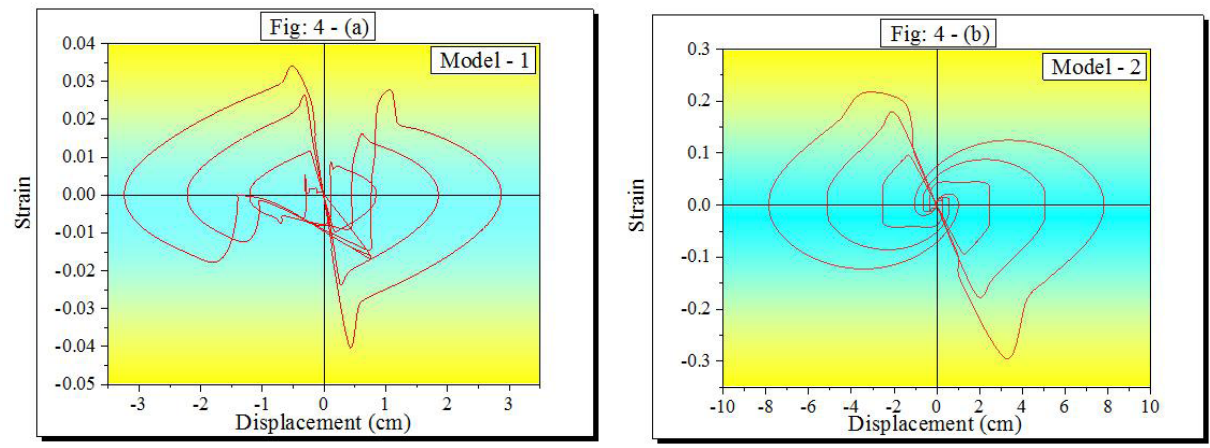

Fig. 4: Strain versus displacement found in timber column models 1 and 2, when the model has been subjected to near-fault ground motion.

The seismic load response versus cyclic nonlinear strain on timber column models 1 and 2 are plotted in Fig. 5. The near-fault ground motion induced cyclic nonlinear displacement and cyclic nonlinear strain, the level of strain and displacement depend on a number of seismic excitation loading. The sensitivity geometry of timber frame allows an earthquake to induce more shaking and it leads to reduction frame strength. A seismic excitation loading applied to the timber frame with the same magnitude produces different strain and settlement mechanism with specific peak level. However, it may cause a dramatic drop-off in the strength of the timber frame at each model differently. When the seismic simulated loading is applied to the model, the most critical condition develops when timber frame is subjected to the mechanical resonance and the strain energy dissipation occurs with a delay due to high oscillate produced by storage strain energy at the model and vibrating model at a specific frequency. The increase in strain energy is intended to provide accelerations in the timber frame. The amplitude at resonance controls the damping ratio. The resonance creates a large displacement and inertia force, however, it leads to failure of timber frame due to the reduction of inertial resistance and developing the mechanical damping and forming the elastic deformation after the meaningfully reducing strength of the timber. The plastic area at timber column leading to decrease storage strain energy in remaining time the nearfault ground motion is applied to the model. The strain energy behavior is important in timber structure seismic response analysis and it significantly depending on frame geometry to be used in a construct timber structure. According to the energy sharing mechanism, when sudden release strain energy it built up deformation and shake model with noticeable magnitude. 

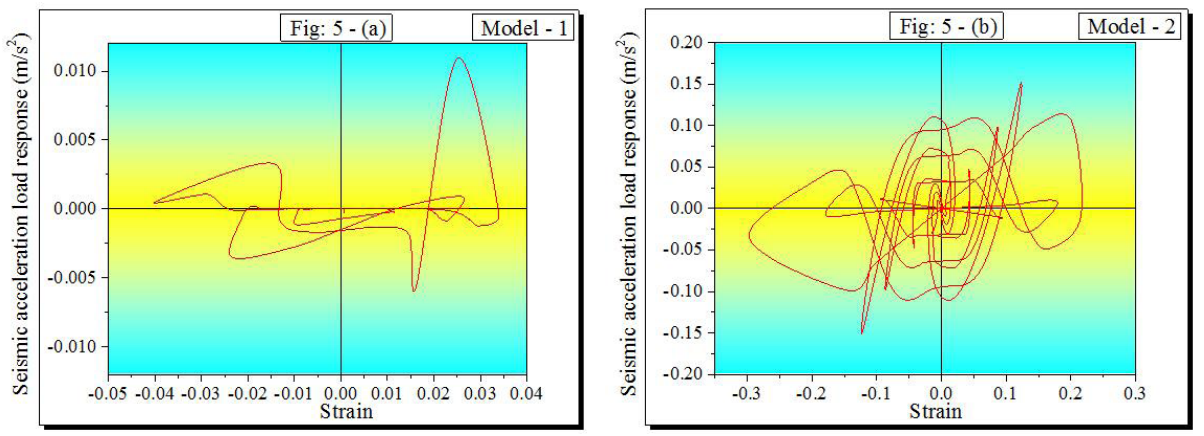

Fig. 5: Seismic response versus strain found in timber column models 1 and 2, when the model has been subjected to near-fault ground motion.

Fig. 6 shows that the larger lateral nonlinear displacement is induced in column characterized by longer frame span. The larger nonlinear deformation has been observed in model 2 . The nonlinear cyclic deformation with higher concentration is observed in model 2.

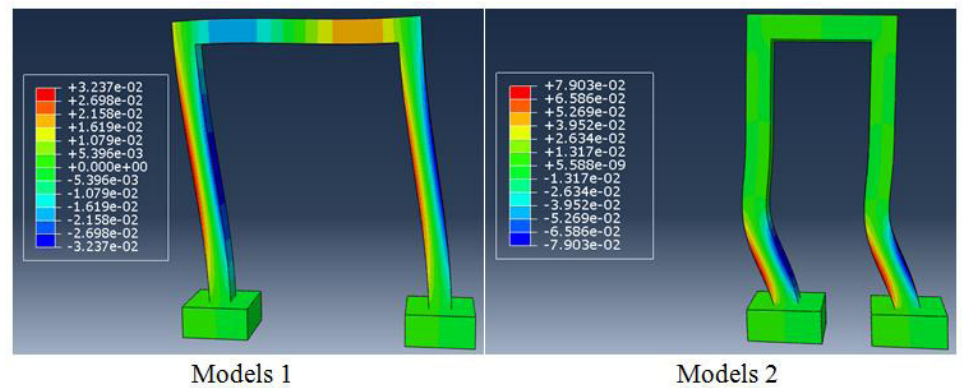

Fig. 6: The cyclic lateral displacement of timber frame (dimension in meters).

The morphology of nonlinear cyclic deformation has been produced based on strain energy characteristics. Significant nonlinear cyclic deformation has occurred within the timber frame and both beam and column experience damage. The noteworthy enlargement wave propagation develops resonance in the majority of the shared load in the form of shearing force mechanism at model 2. The shearing force mechanism is important at design criterion in relation to the timber frame seismic stability. The inappropriate shearing force mechanism leads to the noteworthy enlargement seismic wave propagation effect to the model. The strain energy built up the multidirectional cyclic inertia forces and acts to the mass of timber frame if timber frame exhibit with insufficient inelastic deformation capacity and the unsustainable damage expected. In the present study has been observed that the same near-fault ground motion causes differences multidirectional cyclic inertia forces are subjected to each model, and it leads to developing differences seismic response of these timber frames and different type of failure mechanism at each model. The elastic force and elastic displacement have been occurred with sharing seismic excitation. The damage states in multidirectional cyclic inertia forces refer to strain energy characteristics, and this phenomenon induces cracking, crushing and collapse with minimizing strength and stiffness of timber. The strain energy characteristics are responsible for developing 
softening area at timber beam and column, and it is characterized by failure hardening response and occurrences cyclic nonlinear deformation.

\section{Related work}

In the timber beam, seismic resistance has been reported that the greater displacements occur with the increasing length of the timber beam, and subsequently, the strain energy dissipation, inertial interaction and deformation geometry have been modified (Namdar et al. 2019). With attention to the result of the present study, it can be concluded that with select a timber frame with appropriate span significantly support seismic resistance of timber frame and results in suitable cyclic load sharing in frame elements.

The different types of displacements of the concrete footing have been mitigated with increasing soil-concrete footing interface area (Namdar and Dong, 2019). In the present study, the footing is placed on a rigid surface, the displacements of timber frame alter with change soilfooting interface.

The hysteresis loading influences to the load-bearing capacity of the frame (Stepinac et al. 2019), in the present study, at model 2 , the results of the numerical simulation have coincided with those is presented in the literature.

The combination of a nonlinear finite element analysis and a complex constitutive model will lead to convergence stability problems (Zucchini 2007). Fig. 7 shows in the most wood system at an initial loading no pinching occurs and in second loading cycle pinching starts (Foliente 1995, Baber and Noori 1986).
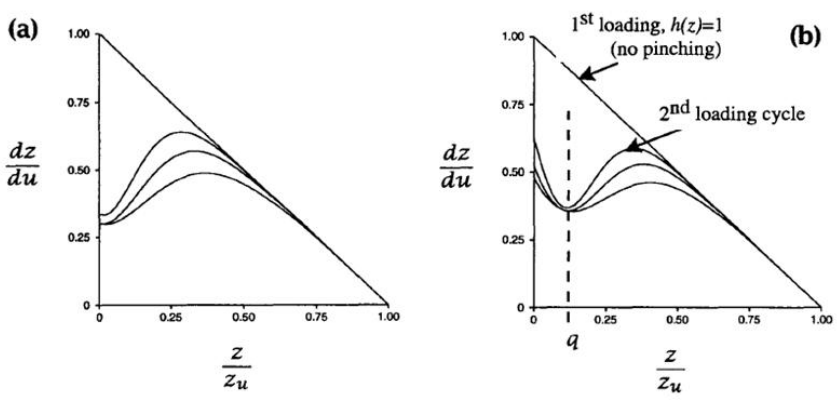

Fig. 7: The pinching under hysteresis mechanism: (a) pinching-function result (Baber and Noori 1986), and (b) pinching for timber (Foliente1995).

The behavior of proposed pinching function for wood systems shows the loading and unloading process leads to initiate fatigue in timber material. It is expected that the model 2 is more vulnerable to fatigue compared to the model one. The reduction of timber structural element fatigue is possible with appropriate timber frame seismic design. Fig. 8 shows, during excitation of the timber frame due to applying cyclic loading, the loading, unloading, and reloading process, the different types of the pinching occur. The following the nature of cyclic loading, three stages of the pinching mechanism included the pinching in the negative direction, positive direction and pinching reach to zero levels have been observed when the timber is subjected to the cyclic loading. During changing the direction of cyclic loading the pinching shape has been changing, while the magnitude of the pinching is related to the nature of the applied load and strength of the timber. Fig. 6 shows, the results of the present numerical analysis 
is in good agreement with Fig. 8. It observed that the results of the present numerical analysis show the seismic timber behavior during the timber frame subjects to pinching. According to Fig. 8, the three stages of pinching mechanism leads to the developing fatigues in the timber frame structural elements if the released strain energy is higher than shear strength and ductility cyclic resistance of the timber structural element and timber frame as well.

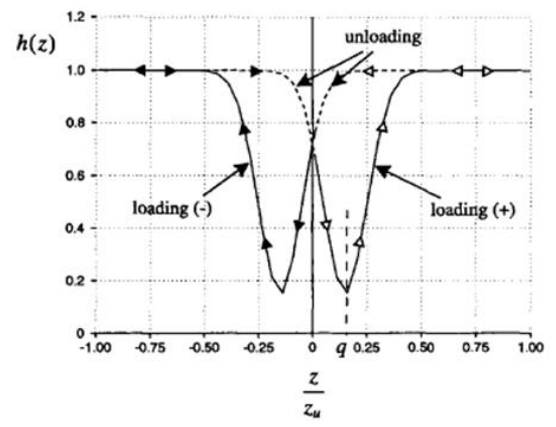

Fig. 8: The pinching mechanism for timber structure (Foliente1995).

After the retrofit a timber structure needs to numerically simulate and design that, it is due to change of timbre structure seismic load response-cyclic displacement, seismic load responsecyclic strain, and cyclic strain-cyclic displacement after the retrofit process. The new resonance appears with new characteristic and develops displacement and inertia force which is different from before retrofit, however, the failure mechanism of timber frame meaningfully modifies, in considering inertial resistance, the mechanical damping ratio, forming the elastic deformation in respect to changing strength and stiffness of the timber.

Timber has high flexibility and seismic resistance compared to other building materials. Where damping ratio, strain energy, and nonlinear deformation are not satisfied, the geometry of timber frame must be modified and it leads to change damping ration and effects to the flexibility and leads to modifying seismic resistance of timber frame. The flexibility of timber frame changes related to the modification of timber frame geometry. The seismic resisting of the timber frame is desirable with architectural space designing through providing sufficient timber frame flexibility. This process is responsible for avoiding frame instabilities due to unallowable $\mathrm{P}-\Delta$ produce at all structural elements. The architecture designer has to consider maximum safe lateral, vertical and rotational flexibility of each frame members with attention to shapes and sizes of the member in order to control damping ratio, strain energy, and nonlinear deformation of the timber frame. The timber structures seismic resistance mechanism is referred to near-fault ground motion, site geomorphology and building architectural design. The multidirectional flexibility of structural elements has a direct relationship with strain energy concentration. The advantageous flexibility of a structural element affects to completed timber frame seismic resistance. The high flexibility of timber frame causes a long period of vibration, in order to have a timber frame with suitable seismic and wind resistance, it needs to design a timber frame with the right flexibility. Although some structural elements have much higher flexibility than others.

The several timber frame structures have been reported in the literature (Namdar et al. 2019, Namdar et al. 2016a, Halicioglu et al. 2014, Palinić and Bjelanović 2016), they have included modern and heritage building and showed to resist well to seismic loading. The results existing in the present study support to design a flexible structure with high seismic resistance characteristic. Using recycled aggregates to make concrete with acceptable durability 
performance, high-performance and self-compacting can be investigated to make the composite timber-concrete structure in the future. It supports to minimize the carbon footprint producing due to construction activities. The timber is eco-friendly and easily recyclable materials as well. However, making a composite timber-concrete cross-section, while the concrete has been made by recycling materials has never been reported in the literature, and can be investigated in the future.

\section{CONCLUSIONS}

The timber elastic frame has been subjected to the near-fault ground motion, and corresponding cyclic nonlinear displacement and cyclic nonlinear strain model have been analyzed. The seismic load response-cyclic displacement, seismic load response-cyclic strain, and cyclic strain-cyclic displacement have been investigated. The critical time of the near-fault ground motion has been zoomed and used in numerical analysis. In the present study the follows goals have been achieved:

- The seismic excitation widespread and cyclic nonlinear displacements cause to the reduction of timber span seismic stability and subsequently significant damage or fully collapse occurs.

- It can be observed that the high difference in peak displacement, and on the other hand from the strain-displacement cyclic paths has been understood that the types of seismic excitation at each model has specific characteristics, and its effects to seismic load transferring and deterioration seismic resistance of the model.

- The results of numerical analysis shown dissipation strain energy at a timber column with the same material and shape significantly were affected by the geometry of the timber frame.

- The sensitivity geometry of timber frame allows an earthquake to induce more shaking and it leads to reduction frame strength.

- The resonance creates a large displacement and inertia force, however, it leads to failure of timber frame due to the reduction of inertial resistance and developing the mechanical damping and forming the elastic deformation after the meaningfully reducing strength of the timber.

- The same near-fault ground motion differences multidirectional cyclic inertia forces are applied to the models, and it leads to developing differences seismic response of timber frames and occurrences different failure mechanism for each model.

\section{REFERENCES}

1. Aktas, Y.D., Akyüz, U., Türer, A., Erdil, B., Sahin Güçhan, N., 2014: Seismic resistance evaluation of traditional Ottoman timber-frame himis houses: Frame loadings and material tests. Earthquake Spectra 30(4): 1711-1732.

2. Androić, B., Čizmar, D., Rajčić, V., 2008: Reliability analysis for laminated timber girders. Građevinar 60(6): 513-518.

3. Arun, G. 2009: Traditional timber construction in Turkey. In: Proceedings of international symposium "Timber structures from antiquity to the present". Istanbul: T.C. Haliç University Press, Pp 113-124. 
4. Ayala, D. D.,Wang, H., 2006: Conservation practice of Chinese timber structures: no originality to be changed, or conserve as found. Journal of Architecture Conservation 12: 7-26.

5. Baber, T., Noori, M. N., 1986: Modeling general hysteresis behavior and random vibration application. Journal of Vibration, Acoustics, Stress and Reliability in Design 108: 411-420.

6. Dackermann, U., Li, J., Rijal, R., Crews, K., 2016: A dynamic-based method for the assessment of connection systems of timber composite structures. Construction and Building Materials 102(2): 999-1008.

7. Daniūnas, A., Gečys, T., 2015: Use of component method in the analysis of timber-steel connections. Građevinar 67(11): 1087-1092.

8. Foliente, G.C., 1995: Hysteresis modeling of wood joints and structural systems. Journal of Structure Engineering 121(6): 1013-1022.

9. Galassi, S., Ruggieri, N., Dipasquale, L.,Tempesta, G., 2018: Assessment of the Moroccan vernacular timber roof: a proposal for an eco-friendly strengthening system. Journal of Architectural Conservation 24(3): 224-248.

10. Halicioglu, F. H., Cakir, F., Demirkesen, S., 2014: Structural assessment of traditional stone-timber houses in Turkey. Građevinar 66(8): 727-737.

11. Jayne, B.A., 1959: Vibrational properties of wood as indices of quality. Forest Product Journal 5: 259-301.

12. Liu, Y., Xiong, H., Kang, J., 2018: Seismic evaluation of wood frame construction based on nail connection deflection status. Wood research 63(6): 979-992.

13. Namdar, A., 2016a: A numerical investigation on soil-concrete foundation interaction. Procedia Structural Integrity 2: 2803-2809.

14. Namdar, A., 2016b: Failure analysis of concrete frame - A numerical analysis. Procedia Structural Integrity 2: 2796-2802.

15. Namdar, A., Darvishi, E., Feng, X., Ge, Q. 2016a: Seismic resistance of timber structure - a state of the art design. Procedia Structural Integrity 2: 2750-2756.

16. Namdar, A., Darvishi, E., Feng, X., Zakaria, I., Yahaya, F.M., 2016b: Effect of flexural crack on plain concrete beam failure mechanism - A numerical simulation. Frattura ed Integrità Strutturale 36(10): 168-181.

17. Namdar, A., Dong, Y., 2019: Seismic resistance and displacement mechanism of the concrete footing. Shock and Vibration, Vol. 2019, Article ID 5498505, 9 pp.

18. Namdar, A., Dong, Y., Liu, Y., 2019: Timber beam seismic design. A numerical simulation. Frattura ed Integrità Strutturale 47(13): 451-458.

19. Palinić, N., Bjelanović, A., 2016: Wooden structures in the historic port of Rijeka. Građevinar 68(10): 801-814.

20. Pizzo, B., Macchioni, N., Lavisci, P., Ciechi, M. De. 2004: On-site consolidation systems of old timber structures. In: C. Bertolini Cestari, T. Marzi, E. Seip, P. Touliatos (Eds.), 2004: Proceedings Interaction between science, technology and architecture in timber construction. Elsevier Science, Heritage Series, Collection Patrimoine, Pp 323-352.

21. Rajčić, V., Bjelanović, A., 2005: Classification of timber. Građevinar 57(10): 779-784.

22. Sandoz, J.L., 1989: Grading of construction timber by ultrasound. Wood Science and Technology 23: 95-108.

23. Soltis, L. A., 1984: Low-rise timber building subjected to seismic, wind and snow. Journal of Structure Engineering 110(4): 744-753.

24. Stepinac, M., Rajčić, V., Barbalić, J., 2017: Inspection and condition assessment of existing timber structures. Građevinar 69(9): 861-873. 
25. Stepinac, M., Rajčić, V., Žarnić, R., 2019: Timber-structural glass composite systems in earthquake environment. Građevinar 68(3): 211-219.

26. Yeh, T. C., Hartz, B. J., Brown, C. B., 1971: Damping sources in wood structures. Journal of sound and vibration 19(4): 411-419.

27. Zucchini, A., 2007: Mechanics of masonry in compression: results from a homogenisation approach. Computers \& Structures 85(3-4): 193-204.

\author{
Abdoullah Namdar*1,2 \\ ${ }^{1}$ Huaiyin Institute of Technology \\ Faculty of Architecture and Civil Engineering \\ HUAI'AN \\ China \\ 2Ton Duc Thang University \\ Adept. for Management of Science and Technology Development \\ Bfaculty of Environment and Labour Safety \\ Ho Chi Minh City \\ Vietnam \\ *Corresponding author: abdoullah.namdar@tdtu.edu.vn
}


